\title{
Development of a Rubric to Assess Lifelong Learning in Work-Integrated Learning Reflection Assignments
}

\author{
Robert Sproule, David Drewery, T. Judene Pretti
}

Lifelong learning has emerged as an important learning outcome across the Canadian post-secondary education system. However, assessments of lifelong learning have been limited to students' self-reports, particularly questionnaires. In programs that offer work-integrated learning experiences, students' reflections may provide a window to further developing this outcome. The purpose of this study was to develop a rubric for assessing lifelong learning in this context. A review of the literature was used to develop both a rubric and self-assessment instrument for measuring lifelong learning. Students in an accounting and financial management co-op program at the University of $W$ aterloo $(n=32)$ completed the self-assessment and the rubric was applied to two reflection assignments. Staff feedback and correlational analyses provide initial support for the rubric as a useful tool for assessing lifelong learning. Implications for educators especially in work-integrated learning contexts are addressed.

Keywords: lifelong learning, reflection, rubric, work-integrated learning

L'apprentissage permanent est devenu un objectif d'apprentissage important dans l'ensemble du système d'éducation postsecondaire canadien. Toutefois, l'évaluation de l'apprentissage permanent s'est limitée jusqu'à maintenant aux témoignages des étudiants, au moyen de questionnaires tout particulièrement. Dans les programmes qui offrent des expériences d'apprentissage intégrées au milieu du travail, les réflexions des étudiants peuvent représenter une occasion de progrès dans ce domaine. L'objectif de notre étude était de concevoir une grille d'évaluation permettant d'évaluer l'apprentissage permanent dans un tel contexte. En nous fondant sur un examen des études existantes, nous avons élaboré cette grille ainsi qu'un outil d'auto-évaluation afin d'évaluer l'apprentissage permanent. Des étudiants inscrits dans un programme d'alternance travail-études en comptabilité et gestion financière de l'Université de Waterloo $(n=32)$ ont complété l'auto-évaluation et nous avons appliqué la grille d'evaluation à deux devoirs d'ordre réflexif. Les commentaires du personnel et l'analyse des corrélations semblent de prime abord indiquer que la grille d'évaluation est un outil utile pour évaluer l'apprentissage permanent. Nous discutons des conséquences de notre étude pour les éducateurs, tout spécialement dans le contexte de l'apprentissage intégré au milieu de travail.

Mots clés : apprentissage permanent, réflexion, grille d'évaluation, apprentissage intégré au milieu de travail 
$\mathrm{W}$ hen we think of concepts that have a positive connotation within education, lifelong learning is one of the first that comes to mind. Lifelong learning has been described as a journey in which people develop their skills and knowledge throughout their lives (Aspin \& Chapman, 2001; Hojat, Veloski, Nasca, Erdmann, \& Gonnella, 2006). Today's world demands that individuals learn not just through formal education during their youth but during all stages of life and across all domains (Billett \& Choy, 2011). Those who subscribe to this perspective argue that a central aim for post-secondary education is to develop students into lifelong learners (Candy, 1991). The School of Accounting and Finance (SAF) at the University of Waterloo recently acknowledged the importance of lifelong learning. SAF alumni have consistently identified lifelong learning as an essential graduate attribute. An emergent goal within SAF has been to better understand how to develop students into lifelong learners and how to assess this development.

\section{A Lifelong Learning Mindset}

A mindset is a collection of beliefs and attitudes with which a person approaches a situation. Dweck (2006) popularized the notion of a mindset in her work regarding growth and fixed mindsets. We acknowledge this work and borrow the term mindset to describe in more detail the characteristics of lifelong learners. A review of the literature suggests that lifelong learners are defined by their lifelong learning mindset. This mindset is a collection of beliefs and attitudes that amount to a self-directed, persistent, and intrinsically motivated drive for new knowledge. Although definitions of a lifelong learning mindset vary, several core concepts best articulate the features of this mindset. These include epistemic curiosity, proactivity, transfer of knowledge, reflection, and resilience.

\section{Epistemic Curiosity and}

\section{Proactivity}

Epistemic curiosity refers to a drive for learning new things both out of interest for those things and to rectify the tension of not knowing (Berlyne, 1960; Litman, 2008). Authors argue that curiosity about things not yet learned is central to a lifelong pursuit of knowledge (Deakin Crick, Broadfoot, \& Claxton, 2004). It acts as a force underlying the things that people do to reach deeper understanding of things, such as persisting through challenges and proactively seeking information. Proactivity, or taking initiative in the learning process, is a second aspect which is common across the lifelong learning literature. Rather than wait for instruction, lifelong learners actively develop a course of action (Candy, 1991). Often this includes setting goals (Kirby, Knapper, Lamon, \& Egnatoff, 2010) and determining where to find information about the topic at hand (Wielkiewicz \& Meuwissen, 2014). Both curiosity and proactivity describe an intrinsic motivation to learn new things in a self-directed way. Curiosity is the motivational state or trait underlying the selfregulated and intentional (i.e., proactive) search for knowledge (Kashdan, Rose, \& Fincham, 2004).

\section{Transfer of Knowledge and Reflection}

Lifelong learners are also described as having a strategic awareness regarding their learning styles and opportunities (e.g., Deakin Crick et al., 2004). Two aspects of a lifelong learning mindset seem most central to this. The first is the transfer of knowledge, which refers to the application of knowledge already acquired to current learning tasks. It has been suggested that lifelong learning is not only lifelong but also lifewide (Jarvis, 2007). That is, lifelong learning is a pursuit that spans across contexts. Lifelong learners make inferences and assumptions 
based on what they already know and experiment with new conditions (Candy, Crebert, \& O'Leary, 1994; Knapper \& Cropley, 2000). Their approach is to make connections across contexts and to apply what they learned in other contexts to their present challenge. The second aspect is that of reflection. Reflection in general is understood as the process of thinking about thinking (e.g., Mezirow, 1991). Lifelong learners monitor what works well and what does not and they reach a level of self-awareness that is believed to be consistent with a deep learning style (Deakin Crick et al., 2004). They reflect on their learning experiences to identify issues as they also plan toward setting new goals for overcoming those issues. In other words, lifelong learners think critically about their experiences in a way that guides their future approaches to learning. Both transfer of knowledge and reflection are core aspects of a lifelong learning mindset. Together they characterize the lifelong learning mindset as one that is critical, intentional, and self-aware.

\section{Resilience}

The lifelong learning mindset features a tendency to persist through learning challenges, and so it is resilient. By contrast, it is difficult to imagine a lifelong quest for knowledge while harbouring a fragile mindset that gives up on learning difficult things (Deakin Crick et al., 2004). As such, the concept of resilience and in particular academic resilience, or a strength to cope with challenges in learning new things (Martin \& Marsh, 2006), is relevant. Authors in the lifelong learning literature commonly refer to adaptation to new demands as being a cornerstone of lifelong learning (Candy et al., 1994; Knapper \& Cropley, 2000). They highlight that persistence over time and returning to progressively more challenging opportunities is central to the lifelong learning mindset (Candy, 1991).

In summary, the literature describes lifelong learners in terms of the lifelong learning mindset. This mindset involves curiosity about learning, taking initiative (e.g., setting goals, looking for information), drawing from previous experiences (transfer), and reflecting on and overcoming challenges.

\section{Development of a Lifelong}

\section{Learning Rubric}

Despite agreement about the value of lifelong learning, assessing lifelong learning remains problematic. To date, no generally accepted means for assessing students' lifelong learning mindsets have been established. Several self-report instruments have been offered (e.g., Hojat et al., 2003; Kirby et al., 2010; Wielkiewicz \& Muewissen, 2014). However, these are used primarily for research purposes. Their usefulness in course settings is perhaps more limited. Specifically, they are limited by a reliance on students' perceptions of their own development and therefore are susceptible to any number of self-report biases.

The School of Accounting and Finance (SAF) at the University of Waterloo was interested in developing an alternative approach to assessing lifelong learning. The alternative approach that we chose to explore was a rubric that could be applied to students' written assignments. This approach was selected for several reasons. First, reflection assignments are common across many programs, including at our institution. Further, they are common in programs that offer experiential education opportunities (Dyment \& O'Connell, 2011) which is that case in SAF.

Second, it has been suggested that written reflection assignments may provide educators with insight into students' approaches to learning and their experiences with learning new things. Educational theorists (e.g., Boud \& Falchikov, 2006; Martin \& Hughes, 2009) maintain that reflection is a process through which experiences are put into context. Reflections are therefore evidence of what students were thinking during a given learning opportunity. 
Other research suggests that how students reflect, such as what they reflect on, is subject to the mindset they have during reflection (O'Connell \& Dyment, 2011). For instance, a student could reflect on a mistake as a learning opportunity (consistent with a lifelong learning mindset) or as a failure (inconsistent with a lifelong learning mindset). How students reflect on their experiences, and thus how they write about those experiences, could reveal which students harbour a lifelong learning mindset. With these key reasons in mind, we sought to develop and test a rubric for the purpose of assessing students' lifelong learning via written reflection assignments.

\section{Our Research Project}

The purpose of our project was to develop a rubric for assessing lifelong learning in work-integrated learning students' written reflections. We conceptualized lifelong learning in terms of the lifelong learning mindset described earlier in this paper (curiosity, taking initiative, transferring ideas, reflecting, and resilience). Our focus throughout the project was in the context of work-integrated learning (WIL) programs in part because of our institutional affiliations and because those programs offer a unique opportunity for students to learn at work and to reflect on their learning experiences. Consequently, they are ideal for using a rubric applied to reflections.

Our project began with a preliminary review of other rubrics that could serve as a basis on which to develop our own. The American Association of Colleges and Universities' (2009) Foundations and Skills for Lifelong Learning VALUE Rubric was identified as a useful foundation. This rubric contains five dimensions of lifelong learning: curiosity, initiative, independence, transfer, and reflection. Two critical changes were made to this rubric in creation of our own. First, the independence dimension was replaced with a resilience dimension. Our review of the literature highlighted the fundamental role of resilience in the lifelong learning mindset, which was not previously addressed in the VALUE rubric. Independence, we believe, is captured adequately by the notion of self-direction that is already implicit in the initiative dimension of the rubric. Therefore, we felt that this replacement created a more complete picture of a lifelong learning mindset.

The second change that was made was to recraft some of the content across the four levels for each dimension on the rubric. The VALUE rubric is concerned with actions performed by students in classroom settings. For example, the content for level four of the transfer dimension reads: "Makes explicit references to previous learning and applies in an innovative (new and creative) way that knowledge and those skills to demonstrate comprehension and performance in new situations." Our interest, alternatively, was in students' thoughts, feelings, and behaviours in the context of their work-integrated learning experiences. Thus, we made several alterations, using the VALUE rubric as a starting point, which resulted in a rubric more generally applicable to workplace settings (see Appendix A).

\section{Data Collection}

We used SAF as a context in which to explore the usefulness of the newly developed rubric. Our process involved three related data sources. Access to all data was approved by the university's institutional review board. The first source of data was SAF students. Students received an email invitation to take part in our project by completing a brief questionnaire about their lifelong learning mindsets. We developed this questionnaire based on our earlier work on the topic of lifelong learning in work-integrated learning settings (Drewery, Nevison, Pretti, \& Pennaforte, 2017) and in consultation with existing self-report instruments (e.g., Kirby et al., 2010). As such, the instrument was 15 items long and borrowed from scales that represented the features of the lifelong learning mindset. Specifically, items 
were adapted from Martin and Marsh's (2006) academic resilience scale, Kirby et al.'s (2003) approaches to work questionnaire, and Litman's (2008) epistemic curiosity scale. A total of 32 students provided usable responses to the questionnaire. They indicated their agreement with each item on the questionnaire using a five-point Likert-type scale where $1=$ strongly disagree and $5=$ strongly agree.

The second source of data was the application of the rubric to students' written reflections. For each of the 32 students who provided responses to the questionnaire, a staff member in SAF was hired to apply the Lifelong Learning Rubric to two different reflections. The first of those assignments is called the Major Reflective Report. This assignment asks SAF students to respond to a series of prompts on their knowledge, skills and values after their first work term. This assignment was due just before the end of the student's first work term. The second reflection is called the Reflection and Personalized Development Plan. This reflection models the components of reflection as identified in this dimension of the Lifelong Learning rubric. SAF students complete it after their second work term, reflecting on their experiences, assessing their development, and then setting learning and development goals consistent with what successful accounting and/or finance professionals do.

This process yielded two different sources of information. One was a set of Lifelong Learning Rubric scores for each of the 32 student participants. Each student received a total of 10 scores, one for each of the five dimensions on the rubric (curiosity, initiative, transfer, reflection, and resilience) which was applied twice (to both reflections). We created a mean score for each assignment by averaging the scores for each dimension on that assignment. These scores were used in correlational analyses (described in the results) to determine whether students' selfreported lifelong learning scores would be associated with the scores given to them via the rubric. We assumed that students would have an adequate degree of self-awareness regarding their own lifelong leaning mindset. We argue, for example, that students can report with sufficient accuracy whether they are curious about learning new things. If this assumption is correct, then we expected to see modest correlations between students' self-reports and the scores assigned to their written reflections by the staff members.

The final source of data in the study was feedback from the individual who applied the rubric. This individual is a professional accountant who has been reviewing and providing feedback on student work term reflections for many years. Having seen thousands of reflections in combination with his own personal work and life experience this person was uniquely qualified to provide a thorough perspective on the quality of the proposed rubric.

\section{Findings}

We present the findings of our project in four parts: the results of the self-report questionnaire, results of the rubric as it was applied to two reflection assignments, the relationship between the self-report and rubric scores, and the feedback provided to us by the SAF staff member who used the rubric.

\section{Results of Self-Reported Lifelong Learning Questionnaire}

We first sought to understand how students responded to the questionnaire administered to them. We found that five of the items on the questionnaire performed very poorly. The key issue for four of these items was a lack of variability in responses between students. This is problematic because those items then provide no information about how students differ. The fifth item was also problematic because it was completely unrelated to the other remaining items. That is, students' responses to that one item were not consistent with their responses to other items. Given that the items 
are theoretically connected because they represent connected aspects of a lifelong learning mindset, they should be correlated. We removed these five items and found the remaining 10-item scale to have strong face validity, a normal distribution (skewness $=.31$, kurtosis $=-.33)$, and adequate reliability $(\alpha=.808)$. The items from the final scale that we used in subsequent analyses are shown in Table 1.

Table 1. Items in the Self-Report Lifelong Learning Questionnaire

\begin{tabular}{|c|}
\hline \\
\hline 2. In my job, one of the main attractions for me is to learn new things. (Curiosity) \\
\hline 3. I think I'm good at dealing with the pressures of learning new things at work. (Resilience) \\
\hline $\begin{array}{l}\text { 4. When learning something new at work, I take a step back to see what I know now versus what I knew } \\
\text { before. (Reflection) }\end{array}$ \\
\hline $\begin{array}{l}\text { 5. In trying to understand new ideas, I try to relate them to real life situations to which they might apply. } \\
\text { (Transfer) }\end{array}$ \\
\hline $\begin{array}{l}\text { 6. Some of the issues that crop up at work are so interesting that I pursue them though they are not part of } \\
\text { my job. (Curiosity/Initiative) }\end{array}$ \\
\hline 7. If conditions aren't right for me at work, I generally manage to do something to change them. (Initiative) \\
\hline 8. When setting work-related goals, I consider how things are going and how I can improve. (Reflection) \\
\hline 9. I apply knowledge I’ve gained from previous experiences to problems that arise at work. (Transfer) \\
\hline 10. During my work terms, I think about my strengths and weaknesses. (Reflection) \\
\hline $\begin{array}{l}\text { Notes: Responses are on a five-point Likert scale where } 1=\text { strongly disagree to } 5=\text { strongly agree. Pro } \\
\text { dimension of lifelong learning to which each item belongs is in parentheses. }\end{array}$ \\
\hline
\end{tabular}

The mean score was slightly above the mid-point of the scale $(M=3.84, S D=.49)$. The scores had only a small range, such that the lowest self-reported score was three and the highest was five. That is, in general no students seemed to report that they had low levels of a lifelong learning mindset. Given the nature of the SAF students at this University, we believed that this was a possible characterization of the sample.

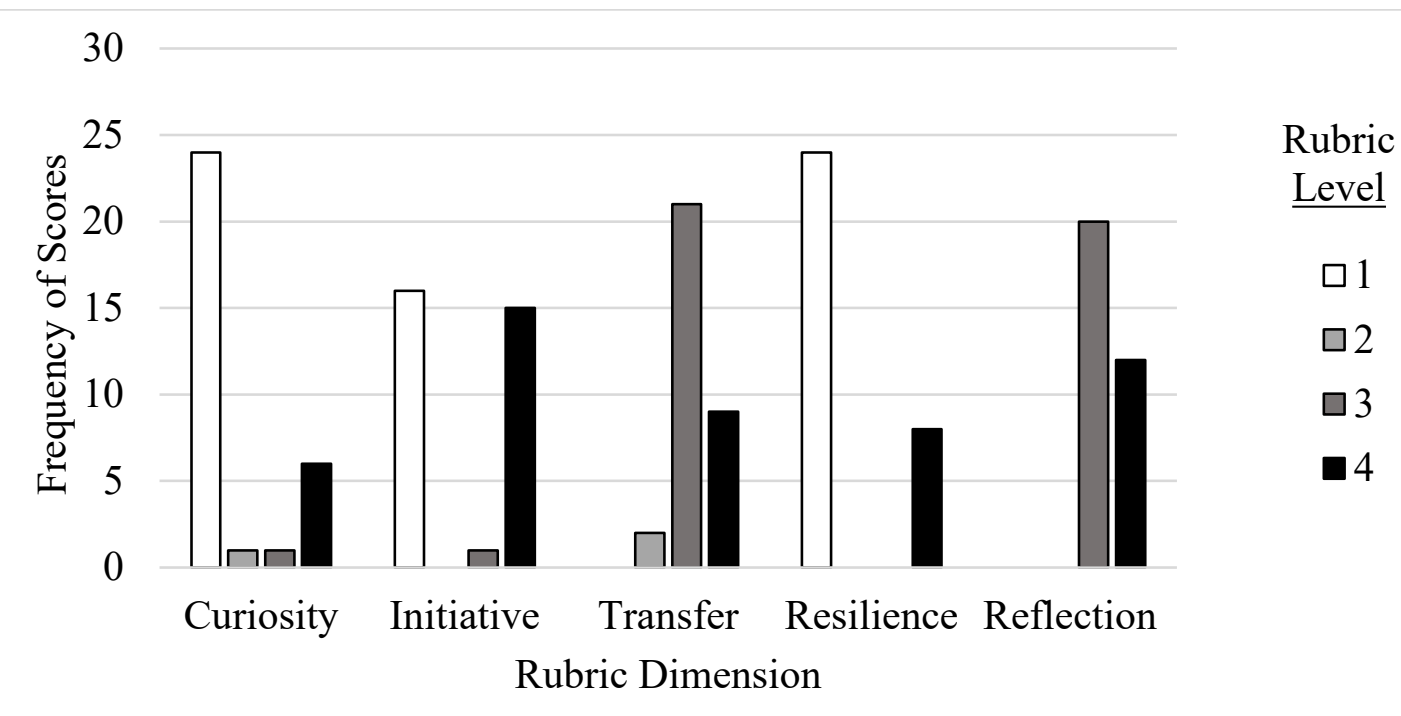

Figure 1. Frequency of scores for the lifelong learning rubric applied to students' Major Reflective Report $(n=$ 32) 


\section{Distributions of Rubric Scores}

We also examined the distribution of the rubric scores. We counted the number of students who received each score (from level 1 to level 4) for each of the five dimensions on the rubric for each of the two assignments to which the rubric was applied. Figures 1 and 2 show the distribution of scores for the two reflections.

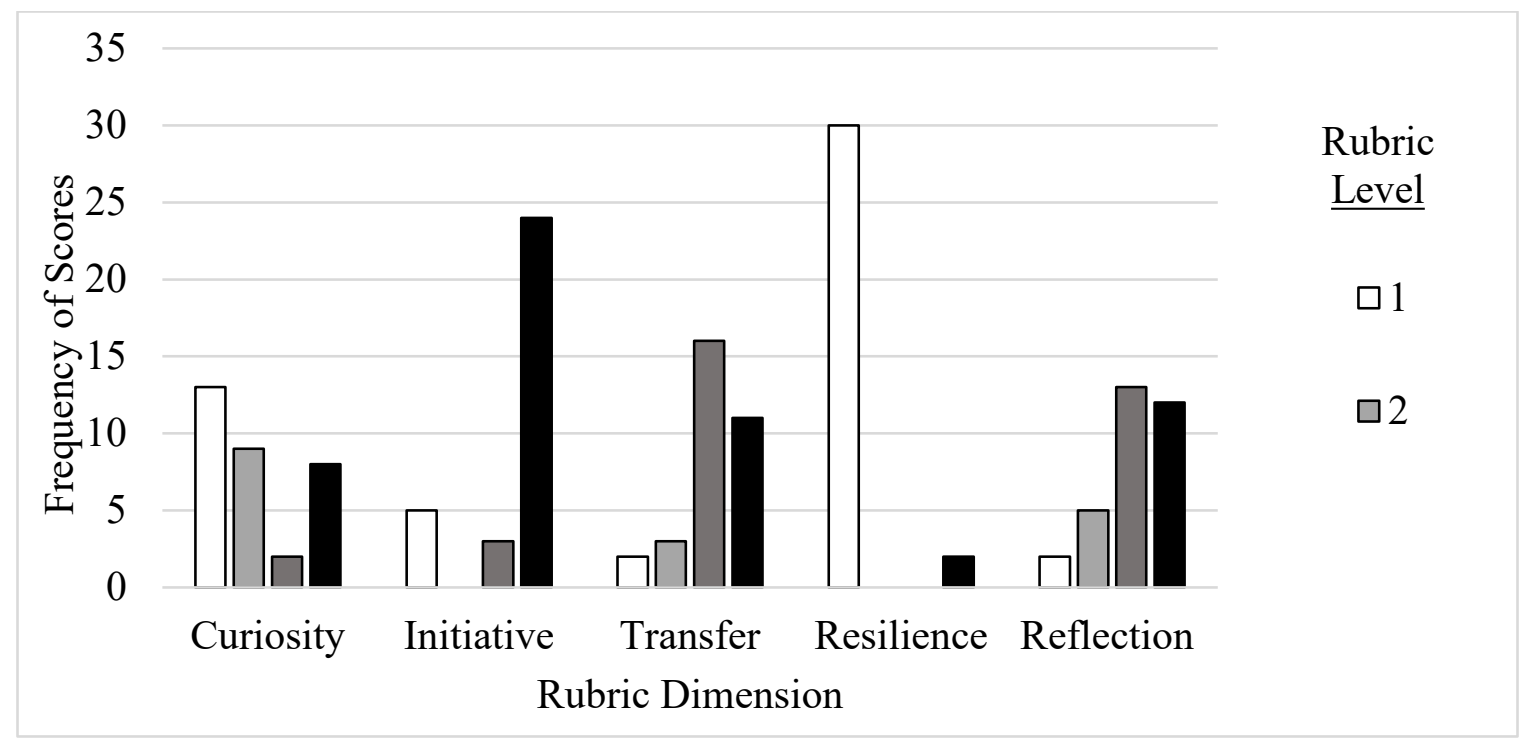

Figure 2. Frequency of scores for the lifelong learning rubric applied to students' Reflection and Personalized Development Plan $(n=32)$

The visual depictions of the distribution of scores suggest that scores for the curiosity and taking initiative dimensions might differ between the two assignments. However, paired samples t-tests revealed that taking initiative but not curiosity scores differed. Specifically, taking initiative scores in Major Reflection assignment $(M=2.47, S D=1.50)$ were

lower than on the Reflection and Personalized Development Plan $(M=3.44, S D=1.11), t(31)=$ $3.20, p<.01$. The figures also suggest that scores for transfer and reflection seem to be quite positive and that they do not differ between assignments. There were no significant differences between the two assignments according to paired sample t-tests. Scores for resilience appear to be the lowest of all dimensions, given the significant proportion of students who received the lowest level of resilience on both assignments. Comparing scores for this dimension between the two assignments shows that scores for resilience were somewhat higher on the Major Reflection assignment $(M=1.75, S D=1.32)$ than on the Reflection and Personalized Development Plan $(M=1.19, S D=.74), t(31)=$ $2.68, p<.05$. When comparing the average of all dimensions between the two rubrics, results suggest that scores on the Major Reflection assignment $(M=$ $2.49, S D=.67)$ did not differ from those on the Reflection and Personalized Development Plan $(M=$ 2.60, $S D=.65), t(31)=.79, p=.44$.

\section{Correlations between Self-}

\section{Reports and Rubric}

We examined the correlations between students' selfreports and the scores for each assignment. Results show that students' self-reported lifelong learning mindset is moderately correlated with Major 
Reflective Report scores $(r=.42, p<.05)$. That is, students who reported higher (compared to lower) lifelong learning mindsets received higher scores on their major reflection assignments, according to the rubric. The pattern was similar for the Reflection and Personalized Development Plan reflection, but was not statistically significant $(r=.30, p=.10)$. With a larger sample size, it is likely that this degree of correlation would be significant. Scores between the major reflection assignment and the work term reflection assignment also approached significance $(r$ $=.34, p=.06)$. This suggests some degree of consistency in use of the rubric for each student. Students who scored higher on one of the reflection assignments also scored higher on the other. Of course, the quality of students' reflections is based on many factors (O'Connell \& Dyment, 2012). Still, this suggests that, with a larger sample size, one would likely find that the rubric is consistent for each student.

\section{Experience of Using the Rubric}

We reviewed the feedback provided by the individual who applied the rubric to better understand whether the rubric would be useful to course instructors. Several key insights were obtained from this review. First, it became clear that the experience of applying the rubric was impacted by the prompts provided for writing the reflection. That is, it was easier to apply the rubric to a reflection which was designed to showcase students' lifelong learning than to a general reflection.

Second, it was acknowledged that reflections in general can be appropriate spaces in which instructors may assess lifelong learning. All five dimensions proposed in the rubric were present to varying degrees in students' reflections and the assessor had little difficulty differentiating between low and high levels for each dimension. For instance, there was little issue in differentiating those students who were curious from those who were less curious.
Curious students wrote about inventing new ways of accomplishing tasks while others did not. Similarly, the rubric was able to detect varying levels of resilience depending on the extent to which students were thrust into unexpected situations which caused them to take on new job responsibilities that they did not anticipate.

A significant insight from the assessor's comments was that it was difficult to differentiate curiosity from taking initiative. Reflections seemed to feature behaviours more than affective aspects of the work term experience, and so what was assessed was typically what students did, not what they felt. The assessor noted the following:

I also found that students scoring well in this category also scored well in the curiosity category, which I don't think is coincidence since to look beyond established processes/procedures, students often took initiative of some degree to demonstrate the behaviour.

This is problematic as it disagrees with our initial conceptualization of lifelong learning.

Based on recent research and our observations on curiosity (see Kashdan et al., 2018), it clearly reflects more of an affective aspect of lifelong learning than does taking initiative, which is more clearly observable. As such, it was suggested that the curiosity dimension be revised to better reflect the quest for knowledge specifically, rather than proactive behaviours that are more specific to tasklevel performance at work. That is, it could be useful to conceptualize curiosity more specifically as epistemic curiosity, as mentioned earlier in this article (e.g., Litman, 2008) and taking initiative more specifically as proactivity as it is described in the organizational behaviour literature (e.g., Grant \& Ashford, 2008).

Finally, the experience of applying the rubric revealed that our initial conceptualization of resilience was 
limiting and did not represent the scope of resilient action described by students. The literature surrounding resilience, which tends to include coping with failure and clearly privileges academic contexts (e.g., Martin \& Marsh, 2006), may not account for the wide range of examples of resilience evidence in reflections. Resilience was not just about bouncing back from mistakes and failures but rather had to do with overcoming even small challenges, such as dealing with uncertainty at work. In this way, accounts of resilience presented by students rarely included large problems which needed to be overcome and instead featured ways in which they navigated common and daily stressors such as work demands. As such, the resilience dimension should be modified to include how a student handles unexpected work place situations that arose during the course of the work term.

\section{Discussion}

The purpose of our ongoing project is to develop new approaches for the assessment of students' lifelong learning mindsets in the context of workintegrated learning (WIL). Dweck's (2006) initial description of a mindset informed a description of a lifelong learning mindset as the beliefs and attitudes that facilitate a particular approach to learning new things, one characterized by curiosity and proactivity, transfer of knowledge and self-reflection, and resilience to challenges. In this paper, we described one way to assess this mindset: a rubric that can be applied to students' reflection assignments. Assignments of this nature are common in many programs, especially those that offer WIL. As such, a contribution of this paper is initial support for the proposed rubric. The experience of using the rubric to assess students' assignments was mostly intuitive. Students' self-reports were somewhat consistent with scores obtained by the rubric. Under the assumption that students have insight into their own lifelong learning mindsets, as has been the case in previous research (e.g., Deakin Crick et al., 2004; Kirby et al.,
2010), this result suggests that this initial version of the rubric has some validity as an assessment tool.

\section{Limitations and Future Research}

We suggest that the rubric provides a useful framework for assessing lifelong learning through written reflection-based assignments. However, it should be noted that the analyses presented in this paper are part of an ongoing project. Our work continues to build off what is described here, in part because of some limitations in the initial study. Due to course sequencing and students' responses to our call for participation, data for only 32 students were collected. Although this sample is large enough to conduct an initial evaluation of the rubric (e.g., distribution of scores, comparison of scores between assignments, and correlations between rubric and self-reports), further research with larger samples is required to more rigorously test the rubric. At present, we are pursuing new opportunities for testing the rubric in a larger sample.

Further, it was evident that the rubric was useful in differentiating scores for some aspects of lifelong learning but not others. For instance, the distribution of students across the four rubric levels for the resilience dimension was bimodal on both assignments. Students were assessed as being entirely resilient or not at all resilient. Naturally, resilience would be something that students have to varying degrees (Martin \& Marsh, 2006). This suggests that the content and wording of the rubric needs to be adjusted in order to clarify and simplify instructions to the assessor. Our goal at present is to edit the rubric to make it easier for use by instructors. Future research to this end will include multiple graders and an analysis of inter-rater reliability, which is a cornerstone of rubric development (e.g., Bresciani et al., 2009).

The correlations between the scores obtained through the application of the rubric and students' 
self-reports of lifelong learning depend on the nature of the self-report instrument. A different instrument might identify different degrees of correlation between the rubric and students' self-assessments. Consequently, we acknowledge the need for additional research that focuses on the self-report instrument. Studies that examine the self-report instrument in different samples of participants may be useful. For instance, it could be useful to compare self-reported lifelong learning characteristics between students and new graduates or alumni. Further scale development studies, such as those which critically evaluate the factor structure of the items would provide further options to instructors who seek to assess lifelong learning characteristics.

\section{References}

Association of American Colleges and Universities. (2009). Foundations and Skills for Lifelong Learning VALUE Rubric. Retrieved from: https://www.aacu.org/sites/default/files/f iles/VALUE/LifelongLearning.pdf

Aspin, D. N., \& Chapman, J. (2001). Towards a philosophy of lifelong learning. In D. N. Aspin, J. Chapman, M. Hatton, \& Y. Sawano (Eds.), International Handbook of Lifelong Learning (pp. 3-34). New York, NY: Springer.

Berlyne, D. E. (1960). Conflict, arousal, and curiosity. New York: McGraw-Hill.

Billett, S., \& Choy, S. (2011). Cooperative and workintegrated education as a pedagogy for lifelong learning. In R. K. Coll \& K. E. Zegwaard (Eds.), International Handbook for Cooperative and Work-Integrated Education: International Perspectives of Theory, Research and Practice (2nd ed., pp. 25-30). Waikato, NZ: WACE.

Boud, D., \& Falchikov, N. (2006). Aligning assessment with long-term learning. Assessment and Evaluation in Higher Education, 31(4), 399-413.
Bresciani, M. J., Oakleaf, M., Kolkhorst, F., Nebeker, C., Barlow, J., Duncan, K., \& Hickmott, J. (2009). Examining design and inter-rater reliability of a rubric measuring research quality across multiple disciplines. Practical Assessment, Research, \& Evaluation, 14(12), 17.

Candy, P. C., Crebert, G., \& O'Leary, J. (1994). Developing lifelong learners through undergraduate education. Canberra, Australia: National Board of Employment, Education, and Training.

Candy, P. C. (1991). Self-direction for lifelong learning: $A$ comprehensive guide to theory and practice. San Francisco, CA: Jossey-Bass

Deakin Crick, R. Broadfoot, P., \& Claxton, G. (2004). Developing an effective lifelong learning inventory: The ELLI project. Assessment in Education: Principles, Policy, \& Practice, 11(3), 247-272.

Drewery, D., Nevison, C., Pretti, T. J., \& Pennaforte, A. (2017). Lifelong learning characteristics, adjustment and extra-role performance in cooperative education. Journal of Education and Work, 30(3), 299-313.

Dyment, J. E., \& O’Connell, T. S. (2011). Assessing the quality of reflection in student journals: A review of the research. Teaching in Higher Education, 16(1), 81-97.

Dweck, C. S. (2006). Mindset: The new psychology of success. New York: Ballantine Books.

Grant, A. M., \& Ashford, S. J. (2008). The dynamics of proactivity at work. Research in Organizational Behavior, 28, 3-34.

Hojat, M., Nasca, T. J., Erdmann, J. B., Frisby, A. J., Veloski, J. J., \& Gonnella, J. S. (2003). An operational measure of physician lifelong learning: Its development, components and preliminary psychometric data. Medical Teacher, 25(4), 433-437.

Hojat, M., Veloski, J., Nasca, T. J., Erdmann, J. B., \& Gonnella, J. S. (2006). Assessing physicians' orientation toward lifelong learning. Journal of General Internal Medicine, 21, 931-936. 
Jarvis, P. (2007). Globalisation, lifelong learning and the learning society: Sociological perspectives. London: Routledge.

Kashdan, T. B., Rose, P., \& Fincham, F. D. (2004). Curiosity and exploration: Facilitating positive subjective experiences and personal growth opportunities. Journal of Personality Assessment, 82(3), 291-305.

Kashdan, T. B., Stiksma, M. C., Disabato, D. J., McKnight P. E., Bekier, J., Kaji J., \& Lazarus, R. (2018). The five-dimensional curiosity scale: Capturing the bandwidth of curiosity and identifying four unique subgroups of curious people. Journal of Research in Personality, 73, 130-149.

Kirby, J. R., Knapper, C. K., Evans, C. J., Carty, A. E., \& Gadula, C. (2003). Approaches to learning at work and workplace climate. International Journal of Training and Development, 7(1), 31-52.

Kirby, J. R., Knapper, C., Lamon, P., \& Egnatoff, W. J. (2010). Development of a scale to measure lifelong learning. International Journal of Lifelong Education, 29(3), 291-302.

Knapper, C. K., \& Cropley, A. J. (2000). Lifelong learning in higher education (3rd ed.). London: Kogan Page Limited.

Litman, J. A. (2008). Interest and deprivation factors of epistemic curiosity. Personality and Individual Differences, 44(7), 1585-1595.

Martin, A., \& Hughes, H. (2009). How to make the most of work integrated learning: A guide for students, lecturers \& supervisors. Palmerston North, NZ: Massey University Press.

Martin, A. J., \& Marsh, H. W. (2006). Academic resilience and its psychological and educational correlates: A construct validity approach. Psychology in the Schools, 43(3), $267-$ 281.

Mezirow, J. (1991). Transformative dimensions of adult learning. San Francisco, CA: Jossey-Bass.

O'Connell, T. S., \& Dyment, J. E. (2011). The case of reflective journals: Is the jury still out? Reflective Practice: International and Multidisciplinary Perspectives, 12(1), 47-59.
Sattler, P., \& Peters, J. (2013). Work-integrated learning in Ontario's postsecondary sector: The experience of Ontario graduates. Toronto, ON: Higher Education Quality Council of Ontario.

Wielkiewicz, R. M., \& Muewissen, A. S. (2014). A lifelong learning scale for research and evaluation of teaching and curricular effectiveness. Teaching of Psychology, 41(3), 220-227.

\section{Biographies}

Robert Sproule is a retired faculty member of the School of Accounting and Finance, University of Waterloo. He acts in a consulting capacity to the School on teaching and learning issues, with a focus on learning outcomes.

David Drewery is Research Coordinator, Waterloo Centre for the Advancement of Co-operative Education. His research focuses on service marketing and management, and workplace dynamics in work-integrated learning contexts.

T. Judene Pretti is Director, Waterloo Centre for the Advancement of Co-operative Education. She conducts research in a number of areas related to coop and work-integrated learning, including how the processes within an organization affect the achievement of outcomes for both students and supervisors. 


\section{Appendix A: Lifelong Learning Rubric}

\begin{tabular}{|c|c|c|c|c|}
\hline $\begin{array}{c}\text { Disposition/ } \\
\text { Skill }\end{array}$ & Level 4 & Level 3 & Level 2 & Level 1 \\
\hline Curiosity & $\begin{array}{l}\text { Continually will look beyond } \\
\text { established } \\
\text { processes/procedures (people, } \\
\text { technology, organization)to } \\
\text { make sense of, and complete } \\
\text { assigned tasks; with intense } \\
\text { interest in all aspects of their job } \\
\text { and workplace }\end{array}$ & $\begin{array}{l}\text { Frequently will look beyond } \\
\text { established } \\
\text { processes/procedures (people, } \\
\text { technology, organization) to } \\
\text { make sense of, and complete } \\
\text { assigned tasks; with regular } \\
\text { interest in all aspects of their job } \\
\text { or workplace }\end{array}$ & $\begin{array}{l}\text { Occasionally will look beyond } \\
\text { established } \\
\text { processes/procedures (people, } \\
\text { technology, organization)to } \\
\text { complete assigned tasks; with } \\
\text { mild interest in some aspect of } \\
\text { their job or workplace }\end{array}$ & $\begin{array}{l}\text { Satisfied with using established } \\
\text { processes/procedures (people, } \\
\text { technology, organization) to } \\
\text { complete assigned tasks; with } \\
\text { low interest in any aspect of their } \\
\text { job or workplace }\end{array}$ \\
\hline Taking Initiative & $\begin{array}{l}\text { Identifies an opportunity to } \\
\text { improve performance or a } \\
\text { process: related to their job or in } \\
\text { another area of the organization; } \\
\text { and implements a plan of action. }\end{array}$ & $\begin{array}{l}\text { Identifies an opportunity to } \\
\text { improve performance or a } \\
\text { process: related to their job or in } \\
\text { another area of the organization; } \\
\text { and looks to their supervisor or } \\
\text { peer for direction. }\end{array}$ & $\begin{array}{l}\text { Identifies an opportunity to } \\
\text { improve performance or a } \\
\text { process: related to their job or } \\
\text { in another area of the } \\
\text { organization. }\end{array}$ & Completes assigned work. \\
\hline Transfer & $\begin{array}{l}\text { References existing knowledge, } \\
\text { skills and/or values from } \\
\text { previous academic, work or life } \\
\text { experiences; and applies them in } \\
\text { an innovative way to a task in } \\
\text { the current work term. }\end{array}$ & $\begin{array}{l}\text { References existing know ledge, } \\
\text { skills and/or values from } \\
\text { previous academic, work or life } \\
\text { experiences; and shows } \\
\text { evidence of directly applying } \\
\text { them to a task in the current } \\
\text { work term. }\end{array}$ & $\begin{array}{l}\text { References existing } \\
\text { knowledge, skills and/or values } \\
\text { from previous academic, w ork } \\
\text { or life experiences; and } \\
\text { attempts to directly apply them } \\
\text { to a task in the current work } \\
\text { term. }\end{array}$ & $\begin{array}{l}\text { No reference to existing } \\
\text { knowledge, skills and/or values } \\
\text { from previous academic, work or } \\
\text { life experiences. }\end{array}$ \\
\hline Resilience & $\begin{array}{l}\text { Bounces back from a stressful } \\
\text { workplace experience/adverse } \\
\text { situation; choosing not to be } \\
\text { deterred, building confidence } \\
\text { for handling similar situations in } \\
\text { the future. }\end{array}$ & $\begin{array}{l}\text { Eventually bounces back from a } \\
\text { stressful workplace } \\
\text { experience/adverse situation; } \\
\text { will make an effort to persist or } \\
\text { push through in resolving it. }\end{array}$ & $\begin{array}{l}\text { Somew hat bounces back/deals } \\
\text { with a stressful workplace } \\
\text { experience/adverse situation; } \\
\text { makes a minimal effort in } \\
\text { dealing with it with no resolve. }\end{array}$ & $\begin{array}{l}\text { Might acknowledge a stressful } \\
\text { experience/adverse situation in } \\
\text { the workplace but is at a loss for } \\
\text { how to deal with it. }\end{array}$ \\
\hline Reflection & $\begin{array}{l}\text { Reviews their leaming on this } \\
\text { work term including: referring } \\
\text { back to an earlier } \\
\text { reflection/benchmarking, how } \\
\text { they have progressed on the } \\
\text { goals set previously; } \\
\text { assessing/benchmarking their } \\
\text { current knowledge, skills and/or } \\
\text { values; developing specific } \\
\text { goals looking ahead; and putting }\end{array}$ & $\begin{array}{l}\text { Reviews their learning on this } \\
\text { work term including: referring } \\
\text { back to an earlier } \\
\text { reflection/benchmarking; } \\
\text { assessing/benchmarking their } \\
\text { current knowledge, skills and/or } \\
\text { values; and developing specific } \\
\text { goals looking ahead. }\end{array}$ & $\begin{array}{l}\text { Reviews their leaming on this } \\
\text { work term including: } \\
\text { assessing/benchmarking their } \\
\text { current knowledge, skills } \\
\text { and/or values. }\end{array}$ & $\begin{array}{l}\text { Somewhat reviews their current } \\
\text { learning on this work term with } \\
\text { no context in terms of past or } \\
\text { future goals for development, or } \\
\text { assessment/benchmarking of } \\
\text { their current know ledge, skills } \\
\text { and/or values. }\end{array}$ \\
\hline
\end{tabular}

